Explaining Reluctance to Benefit from Others’ Misfortune

$$
\text { Gert-Jan Lelieveld }^{1,2} \text {, Yoel Inbar }{ }^{3} \text {, Eric Van Dijk }{ }^{1,2}
$$

${ }^{1}$ Institute of Psychology, Leiden University, the Netherlands, ${ }^{2}$ Leiden Institute for Brain and Cognition, the Netherlands, ${ }^{3}$ Department of Psychology, University of Toronto, Canada.

In press at Journal of Behavioral Decision Making

Author Note

Correspondence concerning this article should be addressed to Gert-Jan Lelieveld, Institute of Psychology, Leiden University, P.O. Box 9555, 2300 RB Leiden, The Netherlands. Phone: +31(0) $71-5276615$; Fax: +31(0) 71 - 5273080. E-mail: lelieveldgj@,fsw.leidenuniv.nl 


\begin{abstract}
The current article investigates decisions where people are not causing harm to others, but only benefit from the harm. Specifically, we assessed people's willingness to benefit from other's chance-caused misfortunes. In five studies, examining real behavior of individuals in a television game show (Study 1) and using experimental betting tasks (Studies 2-5), we show that people are reluctant to benefit from the misfortunes of others. While in all studies participants' decisions were objectively unrelated to the likelihood of misfortune befalling others, subsequent analyses indicate that people erroneously feel that benefitting from others' misfortune increases the likelihood that such harm will actually occur. The results are discussed in relation to the literature on moral decision making and magical thinking.
\end{abstract}

Key words: Benefitting from others' misfortune; magical thinking; wicked desires; moral decision-making 


\section{Explaining Reluctance to Benefit from Others' Misfortune}

People are sometimes blamed for actions that neither caused harm nor were intended to. For example, websites offering people the chance to bet on how many large hurricanes would hit the United States were taken down due to public outrage (Costigan, 2008), and short selling - where investors bet that a stock will decrease in value - is often seen as immoral and blameworthy (Del Marmol, 2011). These judgments are incompatible with classical theories of blame, according to which actions are considered blameworthy when (a) there is a causal relationship between the action and harm to another, and (b) the action leading to the misfortune is intentional (Shaver, 1995; Shultz, Schleifer, \& Altman, 1981; Weiner, 1995). Rather, they seem to arise from people finding an act blameworthy when it causes the actor to adopt wicked desires-i.e., to "root" for a bad outcome. These (assumed) desires are sufficient to trigger judgments of blame even when the individual has no causal influence over the harm that occurred (Inbar, Pizarro, \& Cushman, 2012).

To date, research has mostly examined this phenomenon in third-party judgments (e.g., Inbar et al., 2012). Very little research has investigated whether a reluctance to benefit from misfortune also affects first-party decisions - that is, whether people are unwilling to put themselves in a position where they benefit from a negative outcome befalling another. In two recent exceptions, Morewedge, Tang, and colleagues found that “disloyalty aversion" leads to a reluctance to bet against identity-relevant desired outcomes (e.g., the victory of their favored Presidential candidate or sports team; Morewedge, Tang, \& Larrick, in press), or against close others (Tang, Morewedge, Larrick, \& Klein, 2017). 
In the current research, we investigate whether a reluctance to benefit from misfortune might apply more broadly — that is, whether people might even be reluctant to bet against more distant others. Moreover, we also investigated the psychological processes that might underlie such a preference. Since we investigate decisions regarding distant others, loyalty concerns are unlikely to come into play. We investigate two possible accounts that might explain this phenomenon: the wicked desires account and the magical thinking account.

Third-party condemnation of benefitting from misfortune follows from assumptions about the individual's underlying desires: Individuals benefitting from harm are seen as possessing a desire for the harm to occur, which in turn leads to moral condemnation (Inbar et al., 2012). In first-party decisions, people may want to shield themselves from such desires. People have a general desire to portray themselves as moral to the outside world (e.g., Aquino \& Reed, 2002) and also to see themselves as moral (Jordan, Leliveld, \& Tenbrunsel, 2015; Monin \& Jordan, 2009), and therefore may be unwilling to put themselves in a position to benefit from misfortune. People may thus choose not to benefit from others' misfortune in order to avoid the desire for the misfortune to occur. Previous research has found evidence of similar self-protective motives in the moral domain. Dana, Cain, and Dawes (2006) (see also Shalvi, Handgraaf, \& De Dreu, 2011) showed that people may avoid putting themselves in situations where they benefit themselves at the expense of others. In their study, participants playing a dictator game most often accepted $\$ 9$ to exit the game, instead of playing the actual game where they could earn a dollar more, but at the expense of another person. These studies showed that people avoid situations where their actions can directly disadvantage 
another. In contrast, we study settings where no such causality or intent regarding the harm is involved. According to this wicked desires account people refrain from benefitting from the misfortunes of others to avoid the desire for these misfortunes to actually occur (see Inbar et al., 2012).

It may also be that people (erroneously) feel that if they put themselves in a position to benefit from a negative event, they actually make the event more likely to occur. We refer to this as the magical thinking account. Magical thinking does not seem to play a large role in third-party judgments of those who benefit from others' misfortune, but it may be that people are especially prone to magical thinking when they themselves are making the decision. Indeed, a large body of research has shown that people sometimes believe that they have caused a desired outcome even when there is no way that they could have done so (Nemeroff \& Rozin, 2000). Previous research has for instance shown that lottery players possess illusions of control regarding their ability to influence chance gambles (Langer, 1975). Most relevant to the current studies, Pronin and colleagues (2006) found that participants who performed a symbolic act of harm (a "voodoo hex") directed at a disliked confederate (whom the participants presumably wanted to harm) felt more responsible for the confederate's subsequent symptoms of physical illness than did those who targeted a neutral confederate. If people believe that by choosing to benefit from a negative event they make it more likely to occur, this could explain a reluctance to benefit from others' losses - even when there is no (non-magical) way that people's choices could actually affect the outcome.

In five studies, we demonstrate that people are indeed reluctant to benefit from others' misfortune. We do this in the strongest setting we could conceive to test our 
predictions, i.e., in a setting where the actual misfortune was entirely determined by chance, and thus beyond the participants' control. We show this in the field-by examining the behavior of individuals in a television game show (Study 1) — and in the lab, using experimental betting tasks (Studies 2-5). In Studies 3 and 4 we focus on the underlying psychological process to test the wicked desires and magical thinking accounts outlined earlier.

\section{Study 1}

\section{Method}

In Study 1 we examined whether people are reluctant to benefit from the misfortunes of others. We examined this question in the context of the Dutch game show Miljoenenjacht, which was later adapted for American audiences as Deal or No Deal. The Dutch version's rules are similar to Deal or No Deal's: There are 26 suitcases, each of which contains one of 26 different cash prizes (in the case of Miljoenenjacht, prizes range from one cent to five million Euros). The contestant chooses one case, and the remaining cases are opened over multiple rounds. Thus, at any point in the game the contestant knows which prizes are still outstanding (because the prizes in opened cases can be eliminated) but does not know which prize is in which case. After each round the contestant is offered a price by the bank at which he or she can sell the initially-chosen case. If the contestant takes the deal, he or she wins the offered amount. After that, the remaining cases are opened one by one for everybody to see their contents. Therefore, the contestant's task at the end of each round is to decide whether to take the bank's offer or to continue playing. The contestant chooses which cases are opened in each round and hopes for the opened cases to contain low-value prizes, because this raises the probability 
that the contestant's case contains a high-value prize and consequently raises the bank's offers (see Figure 1; for an in-depth description of the rules, gameplay, and bank behavior, see Post, Van den Assem, Baltussen, \& Thaler, 2008).

Until the spring of 2010, Miljoenenjacht had one additional interesting feature: although the cases to be opened were chosen by contestants, they were actually opened by audience members. Before opening, the audience member guessed which prize was in his or her case and won a bonus if the guess was correct. It is important to note that this bonus was not based on the value of the prize in the case, but on how many cases were still unopened (and hence on the probability of guessing correctly). Audience members therefore had no financial reason to guess any particular value — any remaining prize was equally likely. Consider, however, the implications of the audience member's choice for his or her happiness relative to the contestant's. An audience member who correctly guessed that his or her case contained a large prize would be in the happy position of winning a bonus, but the contestant would be in the unhappy position of seeing a highvalue prize eliminated. Conversely, an audience member who correctly guessed that his or her case contained a small prize would win a bonus, and the contestant would be in the happy position of seeing a small prize eliminated. An audience member reluctant to benefit from the contestant's misfortune should therefore be less inclined to guess a high value. Note that such a choice would not merely reflect an aversion to being a "bearer of bad news," as the news is good or bad regardless of the audience member's guess. Rather, it would reflect a reluctance to benefit from a harm befalling the contestant. However, this dynamic should only apply before the contestant has made a deal. After the deal is made (i.e., after the contestant has accepted the bank's offer), revealing a 
large prize no longer has negative consequences for the contestant. If anything, seeing a large prize revealed should make the contestant happier, as it validates the decision to accept the bank's offer rather than holding out (because revealing a large prize will decrease the bank's next offer). As mentioned earlier, Miljoenenjacht contestants continue choosing cases to be opened (and audience members can guess their contents) until the contents of all cases are known. This allowed us to compare audience members' guesses before and after the contestant had made a deal. If audience members are reluctant to guess high values only when these would mean a bad outcome for the contestant, they should avoid doing so before the contestant has made a deal, but not afterwards.

Analytic strategy. We were able to obtain all 27 episodes of Miljoenenjacht that had originally aired between December 30, 2007 and April 25, 2010 (before 2007 the show was broadcasted by a public service channel that did not share the episodes, and after 2010 the format of the show was changed such that audience members no longer opened cases). We coded every audience member guess in each episode (675 guesses total). For each guess, we recorded what value was guessed, which values were available, and whether the contestant had already made a deal.

\section{Results}

We computed the difference between the mean values of the remaining cases and the contestant guesses pre- and post-deal. On average, participants guessed lower values pre-deal $($ Mdiff $=-59708.37)$ than post-deal $($ Mdiff $=314964.50)$, paired $t(25)=3.04, p=$ .0054, Cohen's $d=.60,95 \% \mathrm{CI}_{\text {diff }}[121187,628158.6] .^{1,2}$

\footnotetext{
${ }^{1}$ This analysis excludes one episode in which a deal had not been made by the last round (and thus there are no post-deal guesses).
} 


\section{Discussion}

It appears that people are indeed reluctant to benefit from misfortune befalling another: Miljoenenjacht audience members were less likely to guess that the cases they had to open contained high-value prizes when the contestant had not yet made a deal, than when the contestant had made a deal. Note, however, that there was no economic cost to guessing high or low; all guesses were equally likely to be correct, and the audience members' bonuses for correct guesses depended only on how many cases remained to be opened. In Study 2, we employed an experimental setting in which we made it economically costly to avoid benefitting from misfortune.

\section{Study 2}

In Study 2 we examined reluctance to benefit from misfortune in an experimental betting task. We asked participants to bet on a player's performance, and varied whether the profit-maximizing bet was to bet on the other person to win or lose.

\section{Method}

Design and participants. All procedures were approved by the University of Toronto Research Ethics Board. A power analysis revealed that 88 participants were required for $80 \%$ power to detect a medium effect size $(\varphi=.30)$. We aimed for the inclusion of 100 participants in our study. One hundred four undergraduate students at the

\footnotetext{
${ }^{2}$ As a robustness check, we also performed a second set of analyses that accounts for the fact that the set of available options is not consistent across episodes, as different values are eliminated on each round for each episode. Comparing the rank of the value guessed (relative to the available case values) also suffers from the problem that deals are made on different rounds for each episode, and thus the possible ranks pre-and post-deal differ across episodes. We therefore also took an additional analytic strategy, where we compared actual guesses of participants to the expected guesses. In these analyses, each episode is a case with two observations (pre-deal and post-deal), where higher numbers indicate more guessing of high values (compared to what would be expected if guessing were random). We ran analyses examining the frequency with which the highest value, the two highest values, and the three highest values were guessed. These analyses supported our findings, such that audience members guessed high values less than expected predeal, and more than expected post-deal (see supplementary material for a full description of the analyses).
} 
University of Toronto ( 66 females, $M_{\text {age }}=20.03, S D=1.97$ ) participated in exchange for course credit and the chance to win a cash prize. Participants were told that they would be playing a two-person game in which one of them would be assigned to be the "player" and the other would be the "observer." In fact, all participants were assigned the "observer" role, and a confederate always acted as the "player." Both parties started the game with a $\$ 3$ endowment. The player's role was to draw a marble (without looking) from a bowl containing ten red marbles and eleven white marbles. Depending on condition, the player won by drawing a white marble or a red marble. If the player drew a winning marble, the $\$ 3$ was doubled to $\$ 6$; if he or she did not, the $\$ 3$ was lost. Thus, the player could leave with either $\$ 6$ or $\$ 0$.

Participants had the option (but were not obliged) to bet any amount of their $\$ 3$ endowment on the player either winning or losing. A successful bet paid 2-to-1, whereas an unsuccessful bet paid nothing (and the amount bet was forfeited). Participants were randomly assigned to one of two conditions: in one, the profit-maximizing choice was to bet on the player to win; in the other, the profit-maximizing choice was to bet on the player to lose. We varied whether the "win" or "lose" bet was profit-maximizing by varying the winning marble color, and thus the odds of the player drawing a winning marble. When white was the winning color, the player had a $52.38 \%(11 / 21)$ chance of drawing a winning marble, and thus betting $\$ 3$ on the player to win had an expected value of $.5238 \times 2 \times 3=\$ 3.14$. In contrast, when red was the winning color, the player had a $47.62 \%(10 / 21)$ chance of drawing a winning marble, and thus in this condition betting $\$ 3$ on the player to win had an expected value of $.4762 \times 2 \times 3=\$ 2.86$. In each case, of course, the expected value of a $\$ 3$ "lose" bet was $\$ 6$ minus the expected value of 
the "win" bet. A purely self-interested non-risk-averse observer should therefore bet all \$3 on the profit-maximizing option, whether that was for the player to win or lose. Although choosing not to bet could be rational (assuming risk aversion), no rational, purely self-interested observer should bet against the more likely outcome. In contrast, if observers were reluctant to benefit from the player's misfortune, they should be less willing to bet on the profit-maximizing option when that option was the "lose" bet, and might even be willing to bet — against the odds — that the player would win in this condition.

Materials and procedure. Before participants arrived at the lab, they were randomly assigned to condition. Participants were met by an experimenter and a purported second participant (in reality, a confederate). The rules of the game were explained to them, and they were shown the bowl to be used for the drawing. At this point, the participant was always assigned the observer role and the confederate the player role. The confederate did not exchange any information with the participant, and it was clear that they would not meet afterwards. The participant was then taken to an individual cubicle, where he or she completed a comprehension check (if this revealed any problems, the experimenter reviewed the rules of the game until the participant understood them). The participant then made his or her betting decision by filling out a questionnaire that first asked whether he or she wanted to bet for the player, against the player or preferred not to bet. The next question asked, "If you chose to bet, how much would you like to wager? You can write any amount between 1 cent and \$3.00.”

The participant then proceeded to the next page of the questionnaire, which contained six exploratory process measures (these are described in detail in the 
Supplemental Material; none showed differences by condition). Finally, participants indicated how likely they thought a red vs. white marble was to be drawn on a 7-point Likert scale ("Did you think it was more likely that the player would draw a red marble or a white marble?"; 1 = "Red was much more likely," 4 = "Both were equally likely," 7 $=$ "White was much more likely"). We included this last question to guard against the possibility that differences in perceived likelihood explained any between-condition differences in betting.

After these measures were completed, participants were brought to the same room as the confederate and the drawing was actually carried out. Participants were then taken to a separate room where they were paid depending on the outcome and their bet, probed for suspicion (no participants articulated any suspicions) and debriefed.

\section{Results}

We first verified that participants realized a white marble was more likely to be drawn. White was indeed rated as more likely to be drawn, $M=4.80, S D=1.12$, which differed significantly from the scale midpoint of 4 (labelled "Both were equally likely"), $t(103)=7.28, p<.001$. Likelihood ratings did not differ by condition, $t(102)=1.18, p=$ .24 .

We next tested whether betting choices (coded as betting with the odds, betting against the odds, or abstaining) varied by condition. They did, $\chi^{2}(2, N=104)=24.45, p$ $<.001, \varphi=.48$ (see Table 1). When the better-odds choice was to bet on the player to win, $79 \%$ of participants $(42 / 53)$ chose to do so. In contrast, only $31 \%(16 / 51)$ chose the better-odds option when it was a bet on the player to lose. A bet against the odds - which should never be chosen by a rational, purely self-interested decision-maker-was chosen 
by $19 \%$ of participants $(10 / 53)$ when it was a bet on the player to lose, but by $57 \%$ $(29 / 51)$ when it was a bet on the player to win.

Next, we tested whether the dollar amount bet on the profit-maximizing option varied by condition. For this analysis, we coded a bet against the odds as negative; thus a $\$ 3$ bet on the player to win when the "lose" bet offered better odds would be coded as -3 . Choosing not to bet was always coded as 0 . This analysis showed that participants bet significantly more on the better-odds option in the condition where this was a bet on the player to win $(M=1.33, S D=1.89)$ compared to the condition where this was a bet on the player to lose $(M=-.62, S D=2.31), t(102)=4.71, p<.001$.

Finally, we tested whether-consistent with the magical thinking accountparticipants who had bet that a red marble would be drawn subsequently rated that event as more likely (collapsing across conditions). This was the case, $r=.25, p=.015,95 \% \mathrm{CI}$ [.05 - .43]. We should note, however, that this relationship could also result from idiosyncratic (i.e., non-normative) beliefs about the probability of a red marble being drawn causing betting decisions.

\section{Discussion}

Study 2 found that substantial numbers of participants bet against the odds when doing so avoided benefitting from misfortune. We observed this in a setting with minimal contact with the distant other. Choosing not to bet could be rational (assuming risk aversion), but no rational, purely self-interested observer should bet against the more likely outcome. We believe that the most plausible explanation for this behavior is that people are reluctant to put themselves in the position to benefit from harm befalling 
another. We now turn to more extensive tests of the psychological mechanism underlying this preference.

\section{Study 3}

In Study 3 we tested the wicked desires and magical thinking accounts. To do so we created a similar, but simpler, betting task where we measured participants' avoidance of wicked desires and magical beliefs. We designed an anonymous setting without any prior contact between participants and their putative partners.

\section{Method}

Design and participants. All procedures were approved by the Psychology Research Ethics Committee of Leiden University. The study used a two condition (option to benefit: yes vs. no) between-participants design. Although the effect size for Study 2 $(\varphi=.48)$ was higher than what we anticipated $(\varphi=.30)$, to be conservative we decided to use the same sample size. We thus aimed for the inclusion of 100 participants in our study. One hundred fifteen students from Leiden University ( 89 females, $M_{\mathrm{age}}=21.08$, $S D=2.72)$ participated

Procedure. Upon arrival, participants were told that they would play a game with another participant whom they would not meet or see during or after the task and that both players received 3 euro for participation. They learned that the game was played with a bingo cage that contained 10 balls: 5 balls with a dotted print and 5 balls with a striped print. The other player would draw one ball from the cage. In the no benefit from other's loss condition, participants learned that both players had to guess which of the two types of balls (dotted vs. striped) would be drawn from the cage. If they guessed correctly they would double their participation money (and thus would earn 6 euro) and if 
they guessed incorrectly they would just receive the 3 euro. The options of both players were thus identical, such that each player who would correctly guess the outcome of the draw would receive 6 euro.

In the benefit from other's loss condition, participants also learned that they had to guess whether a dotted or striped ball was drawn from the cage (which determined their payoff), but the payoff of the other participant was determined differently. Half of the participants learned that, for the other player, the payoff would be doubled when a dotted ball was drawn from the cage, but he/she would lose the 3 euro when a striped ball was drawn. The other half learned that the other's payoff would be doubled when a striped ball was drawn and lost when a dotted ball was drawn, thereby counterbalancing the type of ball that was advantageous for the other.

After these instructions, participants guessed which ball would be drawn from the cage: a dotted or a striped ball. After indicating their guess, participants filled out a questionnaire measuring participants' wicked desires, magical beliefs and manipulation checks (see supplementary material for other questions we asked, including results).

We assessed participants' avoidance of wicked desires by asking, on a 7-point scale $(1=$ not at all, $7=$ very $m u c h)$, to what extent they agreed with three statements regarding their (un)willingness to put themselves in a position to benefit from misfortune: (I wanted to avoid the desire that the other would lose; I did not want to hope that the other would lose; I did not want to like it that the other would suffer any losses). Participants' answers to the three statements were combined into an index of avoidance of wicked desires $(\alpha=.85)$. 
We assessed participant's magical beliefs by asking, on a 7-point scale $(1=$ not at all, 7 = very much), to what extent they agreed with four statements regarding their beliefs about causing the misfortune: I believe that my choice could influence the outcome of the ball draw; my guess could influence the outcome of the draw from the cage; I made this choice because I did not want to bring misfortunes to the other; I feel responsible for the outcomes of the other. Participants' answers to the four statements were combined into an index of magical beliefs $(\alpha=.83)$.

To ensure that our manipulation was effective we asked participants how the payoff of the other player was determined: $1=$ Like me, the other player had to guess what the outcome was from the draw; 2 = Unlike me, the other player did not have to guess the outcome of the draw. Then, to check that participants in the benefit from other's loss condition took the consequences for the other player more into account than the participants in the no benefit from other's loss condition, we asked participants to what extent they took the consequences for the other player into account while making their guess, on a 7-point scale $(1=$ not at all, $7=$ very $m u c h)$. Finally, in the benefit from other's loss condition, we counterbalanced whether dotted or striped balls were advantageous for the other player. To test whether participants understood correctly, participants in the benefit from other's loss condition were asked which of the following statements was true: $1=$ When a dotted ball was drawn the other player doubled his/her payoff, but when a striped ball was drawn he/she received nothing; $2=$ When a dotted ball was drawn the other player received nothing, but when a striped ball was drawn he/she doubled his/her payoff. 
After answering these questions, participants learned the outcome of the draw, which was randomly determined to be either a dotted or a striped ball. Participants who had guessed correctly were then paid 6 euro $(N=53)$, and participants who had guessed incorrectly 3 euro $(N=62)$. Finally, participants were debriefed.

\section{Results}

\section{Manipulation checks.}

Option to benefit. All participants correctly answered the question about how the payoff of the other player was determined. Moreover, an independent-samples $t$-test on the question to what extent they took the consequences for the other player into account while making their guess showed a significant effect of option to benefit, $t(113)=5.41, p$ $<.001$, Cohen's $d=1.01,95 \%$ CI [1.18 - 2.55], indicating that in the benefit from other's losses condition participants took the consequences for the other into account more $(M=$ $3.76, S D=2.25)$ than participants in the no benefit from other's losses condition $(M=$ $1.89, S D=1.32)$

Dotted vs. striped. All participants in the benefit from other's loss condition correctly answered the question about what would happen to the payoffs of the other player if a dotted or a striped ball was drawn from the cage.

These findings suggest that the manipulation of the option to benefit and counterbalancing the consequence of dotted vs. striped balls were successful.

Guess. A Chi-square test with condition (option to benefit: yes vs. no) as independent variable and participants' guess as dependent variable showed a significant effect of condition, $\chi^{2}(1, N=115)=4.81, p=.03, \varphi=.20$. We conducted follow-up Chisquare tests for each condition separately to compare the choices against chance. In the 
benefit from the other's loss condition participants more often than chance chose the option where they did not benefit from the other's losses, $\chi^{2}(1, N=58)=11.66, p<.001$, $\varphi=.45$. That is, when dotted balls were considered losses for the other 23 out of 29 participants chose striped balls and when striped balls were considered losses for the other 19 out of 29 participants chose dotted balls, which in total resulted in 42 out of 58 participants $(72.4 \%)$ who were reluctant to benefit from the other player's losses. In the no benefit from other's loss condition participant's choices did not differ from chance, $\chi^{2}$ $(1, N=57)=.16, p=.69, \varphi=.05$. That is, 30 participants $(52.6 \%)$ chose striped balls and 27 participants $(47.4 \%)$ dotted balls.

Avoidance of wicked desires. An independent $t$-test on the avoidance of wicked desires ratings revealed no significant effect of option to benefit, $t(113)=1.19, p=.24$, Cohen's $d=.22$, CI [-.27 - 1.08] (overall $M=3.71 ; S D=1.83$ ).

Magical beliefs. An independent $t$-test on the magical beliefs ratings revealed a significant effect of option to benefit, $t(113)=4.87, p<.001$, Cohen's $d=.91,95 \% \mathrm{CI}$ [.69 - 1.65], indicating that when participants had the option to benefit from the losses of the other player participants reported more magical beliefs (i.e., participants thought their guess could influence the outcome more $)(M=3.07, S D=1.50)$ than when participants did not have the option to benefit $(M=1.90, S D=1.02)$.

Mediation analysis. Based on these results, we tested whether the effect of option to benefit on participants' guesses might be mediated by magical beliefs. We first performed a series of (binary logistic and linear) regression analyses with option to benefit as the independent variable, participants' guesses as the dependent variable, and magical beliefs as the mediator. A binary logistic regression analysis showed a significant 
effect of option to benefit on participants' guesses, $B=.86, S E=.40$, Wald's $\chi^{2}(1, N=$ $115)=4.72, p=.03$, Odds Ratio $=2.36,95 \%$ CI $[1.09-5.13]$, and a linear regression analysis showed a significant effect on the mediator, $B=-1.17, S E=.24, p<.001,95 \%$ CI [-1.65 - -.69], consistent with the independent $t$-test results reported above.

Furthermore, a binary logistic regression showed that, while controlling for the option to benefit, magical beliefs significantly predicted participant's guesses, $B=-.38, S E=.17$, Wald's $\chi^{2}(1, N=115)=5.01, p=.03$, Odds Ratio $=.68,95 \%$ CI [.49 - .95]. Finally, when the mediator (magical beliefs) was included in the binary logistic regression analysis, the effect of option to benefit on participants' guesses became non-significant, $B$ $=.47, S E=.43$, Wald's $\chi^{2}(1, N=115)=1.21, p=.27$, Odds Ratio $=1.61,95 \%$ CI $[.69-$ 3.74].

To test whether this mediation was significant, we used a bootstrap method (Preacher \& Hayes, 2004, 2008). A bootstrapped mediation analysis uses re-sampling of raw data to estimate the confidence intervals (CI) of the indirect effects, of which the mediation model consists. We used bootstrapping to estimate the indirect effect option to benefit on participants' guesses with magical beliefs as mediator. Using 10,000 bootstrap re-samples and bias corrected and accelerated intervals (see Preacher \& Hayes, 2008), we obtained confidence intervals that did not contain zero at the $95 \%$ level (lower $\mathrm{CI}=.02$; upper $\mathrm{CI}=1.05)$, indicating significant mediation. Thus, magical beliefs mediated the effect of option to benefit on participants' guesses.

\section{Discussion}

The results of Study 3 provide strong support for the magical thinking account. Mediation analyses showed that participants chose the option that was most beneficial for 
the other person, because they magically believed that their guess could influence the outcome of the draw.

In Study 3 we showed that magical beliefs can explain why participants were reluctant to benefit from others' losses. To further support the magical thinking account, we conducted another study where we more directly manipulated magical thinking. More specifically, in our last study we manipulated whether the harmful event already occurred or not, using a manipulation from a classic study on the role of magical thinking in predicting the outcome of a die role (Rothbart \& Snyder, 1970). We predicted that participants would be less reluctant to benefit from others' misfortunes when the misfortune had already occurred.

\section{Study 4}

\section{Method}

Design and participants. All procedures were approved by the Psychology Research Ethics Committee of Leiden University. The study used a two condition (guess time point: before draw vs. after draw) between-participants design. We again aimed for the inclusion of 100 participants in our study. 115 students from Leiden University (88 females, $M_{\text {age }}=21.30, S D=2.82$ ) participated.

Procedure. The procedure resembled the benefit from other's loss condition of Study 3. That is, participants had to guess the type of ball (dotted or striped) that was drawn from the cage and their payoff was doubled when participants guessed correctly. As in Study 3, they also learned that for the other player the payoff was doubled when a dotted [striped] ball was drawn from the cage, but he/she would lose the 3 euro when a striped [dotted] ball was drawn. 
In the before the draw condition, participants were told that the ball was not yet drawn and that they had to guess whether the other player would draw a dotted or striped ball from the cage. In the after the draw condition, participants were told that the ball was already drawn and that they had to guess whether the other player had drawn a dotted or striped ball from the cage.

Participants then guessed which ball would be/had been drawn from the cage, after which they completed an identical questionnaire as in Study 3. We again assessed participants' avoidance of wicked desires $(\alpha=.90)$ and magical beliefs $(\alpha=.79)$ with the same questions as in Study 3.

To ensure that our time point of the guess manipulation was effective we asked participants when they had to make their guess: $1=$ Before the ball was drawn from the bingo cage; 2 = After the ball was drawn from the bingo cage.

To test whether participants correctly understood what would happen to the payoff of the other player when a dotted vs. striped ball was drawn, participants were asked the same question as in Study 3 (i.e., Which of the following statements is true: $1=$ When a dotted ball was drawn the other player doubled his/her payoff, but when a striped ball was drawn he/she received nothing; 2 = When a dotted ball was drawn the other player received nothing, but when a striped ball was drawn he/she doubled his/her payoff). Note that we again counterbalanced whether a dotted or striped ball was advantageous for the other player. In addition to testing the effects of the draw for the other player, in the current study we also asked participants what would happen to their own outcomes by asking which of the following statements was true: $1=$ If I correctly 
guessed the outcome of the draw I receive 3 euro, if not I receive 6 euro; $2=$ If I

correctly guessed the outcome of the draw I receive 6 euro, if not I receive 3 euro.

After answering these questions (see supplementary material for other questions we asked, including results), participants learned the outcome of the draw. Participants who guessed correctly were then paid 6 euro $(N=67)$, and participants who guessed incorrectly 3 euro $(N=48)$. Finally, participants were thoroughly debriefed.

\section{Results}

\section{Manipulation checks.}

Guess time point. All participants correctly answered the question about when they had to guess which ball was drawn from the cage (before or after the draw).

Dotted vs. striped. All participants correctly answered what would happen to the payoffs of the other player if a dotted or a striped ball was drawn from the cage. One other participant incorrectly answered what would happen to the own payoffs if he/she guessed correctly or not. Removing this participant from further analyses did not change any of the results, so we decided to not remove this participant from analyses.

These findings suggest that the manipulation of the time point of the guess and counterbalancing the consequence of dotted vs. striped balls were successful.

Guess. A Chi-square test with guess time point as independent variable and participant guess as the dependent variable showed a significant effect of guess time point, $\chi^{2}(1, N=115)=5.21, p=.03, \varphi=.21$. Participants more often chose not to benefit from the other player's losses before the ball was drawn (43 out of 57: 75.4\%), than after the ball was drawn (32 out of 58: 55.2\%). 
Avoidance of wicked desires. An independent $t$-test on the avoidance of wicked desires ratings revealed no significant effect of guess time point, $t(113)=-.33, p=.74$, Cohen's $d=.06,95 \%$ CI $[-.85-.61]$ (overall $M=3.64 ; S D=1.97)$.

Magical beliefs. An independent $t$-test on the magical beliefs ratings revealed a significant effect of guess time point, $t(113)=2.42, p=.02$, Cohen's $d=.46$, CI [.111.14], indicating that before the ball draw participants reported more magical beliefs $(M=$ $2.74, S D=1.47)$ than after the ball draw $(M=2.12, S D=1.29)$.

Mediation analysis. A binary logistic regression analysis showed a significant effect of guess time point on participants' guesses, $B=.92, S E=.41$, Wald's $\chi^{2}(1, N=$ $115)=5.09, p=.02$, Odds Ratio $=2.50,95 \%$ CI $[1.13-5.52]$, and a linear regression analysis showed a significant effect on the mediator, $B=-.63, S E=.26, p=.02,95 \% \mathrm{CI}$ [-1.14 - -.11]. Furthermore, a binary logistic regression showed that, while controlling for the guess time point, magical beliefs significantly predicted participant's guesses, $B=$ $1.04, S E=.24$, Wald's $\chi^{2}(1, N=115)=18.44, p<.001$, Odds Ratio $=.36,95 \%$ CI $[.22-$ .57]. Finally, when the mediator (magical beliefs) was included in the binary logistic regression analysis, the effect of guess time point on participants' guesses became nonsignificant, $B=.58, S E=.46$, Wald's $\chi^{2}(1, N=115)=1.59, p=.21$, Odds Ratio $=1.79$ $95 \%$ CI $[.72-4.44]$.

In line with these regression analyses, a bootstrapped mediation analysis using 10,000 bootstrap re-samples and bias corrected and accelerated intervals showed confidence intervals that did not contain zero at the $95 \%$ level (i.e., lower $\mathrm{CI}=.11$; upper $\mathrm{CI}=1.42$ ), indicating that magical beliefs mediated the effect of guess time point on participants' guesses. These findings thus show that magical thinking plays an important 
role in people's decision to benefit from others' misfortunes. When the misfortune had not yet occurred, participants magically believed they could influence the outcomes of the other. When the misfortune had already occurred, participants experienced less magical beliefs and had no problem benefitting from the loss of the other.

\section{Study 5}

Our first four studies show that people are reluctant to benefit from others' misfortune. In Study 1, the contestant, the studio audience, and thousands of people are watching the show. Decisions about whether to benefit from the losses of the contestant or not could have been influenced by self-presentational concerns. Although Studies 2-4 were more controlled lab experiments, one may believe that these presentational concerns could also have influenced participants decisions in these studies. If people recognize that observers think that benefitting from others' misfortune is morally blameworthy (see Inbar et al., 2012), it is reasonable that they choose to avoid such negative evaluations. To study the influence of such presentational concerns, we ran an additional study, resembling the procedure of Studies 3 and 4, where participants made their decision in a private setting or in a public setting.

\section{Method}

Design and participants. All procedures were approved by the Psychology Research Ethics Committee of Leiden University. The study used a two condition (decision setting: private vs. public) between-participants design. We again aimed for the inclusion of 100 participants in our study. One hundred students from Leiden University (71 females, $\left.M_{\text {age }}=20.49, S D=2.57\right)$ participated. 
Procedure. The procedure resembled the benefit from other's loss condition of Study 3. In the private setting, participants filled out their guess on a paper after which they were instructed to put it in their pocket and not show it to anyone. At the end of the task they were asked to show the paper with their guess to the experimenter. In the public setting, participants filled out their guess on the paper and were instructed to slide the paper under the door. The experimenter would then read it and give it to the other player.

To ensure that our private vs public manipulation was effective we asked participants how they had to make their guess: $1=I$ had to put the paper in my pocket and therefore nobody knows what I guessed; 2 = I had to slide the paper under the door and the other player therefore knows what I guessed.

After answering these questions (see supplementary material for other questions we asked, including results), participants learned the outcome of the draw. Participants who guessed correctly were then paid 6 euro $(N=53)$, and participants who guessed incorrectly 3 euro $(N=47)$. Finally, participants were thoroughly debriefed.

\section{Results}

\section{Manipulation checks.}

Private versus public setting. Two participants incorrectly answered how they had to make their guess (in a private versus public setting). Removing these participants from further analyses did not change any of the results, so we decided to not remove them from analyses.

Guess. A Chi-square test with private versus public setting as independent variable and participant guess as the dependent variable showed a non-significant effect of guess time point, $\chi 2(1, \mathrm{~N}=100)=.19, p=.83, \varphi=-.04 .34$ out of 50 participants in 
the private condition chose not to bet on the misfortunes of the other and 36 out of 50 in the public condition. When collapsing across conditions, participants more often than chance chose the option where they did not benefit from the other's losses, $\chi^{2}(1, \mathrm{~N}=$ $100)=16.00, p<.83, \varphi=.4$. These findings showed that participants were reluctant to benefit from the loss of the other, regardless of whether the decision was made in private or in public.

\section{General Discussion}

Results of five studies show that people are reluctant to benefit from the misfortunes of others, even when doing so cannot affect others' outcomes. We found these effects examining behavior of audience members in a TV game show and in experimental betting tasks. Moreover, we found that people avoid betting on the misfortune of others even when they would benefit financially from doing so (Study 2), and regardless of whether the decision was made in private or in public (Study 5). Finally, with regard to the underlying process, our findings support the magical thinking account. People seem to believe that a decision that would prove beneficial for themselves at the expense of others increases the likelihood that such harm will actually occur. Our fourth study further supports this explanation, by showing that people were only reluctant to benefit from others' misfortunes when the misfortune had not yet occurred. When the misfortune had already occurred, participants experienced less magical beliefs and had no problem benefitting from the losses of others, suggesting that the emotional pay off of being in a win-win situation where both parties gain money cannot fully account for the results. These findings are in line with previous work on magical thinking and the illusion of control, where people bet more money on the 
outcome of a die roll before it was rolled than after it was rolled (Morewedge \& Buechel, 2013; Rothbart \& Snyder, 1970; Strickland et al., 1966; Thompson et al., 1998).

Our five studies show that when people have to make the decision to benefit from others' misfortunes, they refrain because of their magical beliefs. When judging the behavior of others, however, magical beliefs do not seem to play a role (see Inbar et al., 2012). This corroborates previous research that has shown that in chance and gambling tasks people experience more magical beliefs when they are actively involved in the task (i.e., when they make the decision themselves) than when they are not (i.e., when other people are making decisions; e.g., Langer, 1975; Wortman, Cortanzo, \& Witt, 1973). Future research could directly compare first- and third-person perspectives, to investigate the differential role of magical thinking in the decision to benefit from others' misfortune or not.

Until recently, there was very little research investigating people's willingness to benefit from others' misfortune. Morewedge, Tang, and colleagues (Morewedge et al., in press; Tang et al., 2017) have recently advanced an account of reluctance to benefit from misfortune based on self-signaling of (dis)loyalty. According to this "disloyalty aversion" account, people are reluctant to benefit from misfortune to the extent that doing so would signal (to themselves) disloyalty to a close other or personally important group (e.g., a sports team). Thus, they are more willing to bet against a distant other, or even themselves, than to bet against a friend (Tang et al., 2017).

Note that in our studies, participants were unwilling to bet against distant others. Thus, our findings show that when dealing with even distant others, people may be reluctant to benefit from others' misfortune. One difference between the studies where 
Tang et al. (2017) looked at distant others and our studies, is that Tang et al. (2017) portrayed the distant others as out-group members (i.e., a non-business school student), whereas we described the other as a fellow participant whom they did not know. Future research should investigate this distinction between different types of distant others more thoroughly, by making group membership more or less salient.

Another difference with the work of Morewedge, Tang, and colleagues and the research reported here is that we found that people's reluctance to benefit from harm is motivated partly by magical thinking. The findings of the current studies show that magical beliefs can explain why people are reluctant to benefit from the misfortunes of distant others. Magical thinking, however, did not explain why participants in the Tang et al. (2017) paper were less willing to bet on the misfortunes of friends than on acquaintances/strangers. Belief in magical thinking is a general belief that we may form independently of the identity of others we connect to. As such, it most likely operates independently of whether we are making decisions that involve close others or more distant others, and independently of whether we have identity-based relations with these others. Consequently, one would not expect differences in magical thinking to underlie the target effects. Indeed, the studies by Tang et al. (2017) suggest they do not. When it comes to explaining identity-related effects (like a greater reluctance to benefit from close others than from more distant others), loyalty concerns may thus have great explanatory power. However, when it comes to explaining a general reluctance to benefit from other's misfortune, independent of the specific connection you feel to a specific target, the general belief in magical thinking does seem to have great explanatory power. As such, our current insights provide a useful complement to the identity-based account 
of Tang et al. (2017). Future research may focus on how the two accounts may jointly operate and explain both general and target-specific reluctance to benefit from others' misfortune.

Implications and Future Directions. The current work contributes to the field of moral decision-making. Previous work on moral decision-making that involves harm to other people mostly focuses on situations where people make decisions that inflict harm on others, such as the trolley dilemma situation (Cushman et al., 2006; Greene et al., 2001; Hauser et al., 2007). The current work extends this work on moral decision-making by investigating moral decisions of people where no causality regarding the harm is involved. We show that even in situations where individuals do not have any influence on the outcomes of another person, they still take the outcomes of the other person into account when making their decision. For these moral decisions, magical beliefs seem to play an important role in guiding people's choices.

Considering that our findings have implications for moral decision-making, one may wonder whether people's preferences to see themselves as moral or to come across as moral to others may have influenced participants' reluctance to benefit from other's misfortune. Previous research has shown that decisions to behave immorally are indeed influenced by the desire of people to see themselves as moral (Mazar, Amir, \& Ariely, 2008) or come across as moral to others (Aquino \& Reed, 2002), which suggests that such concerns are possible additional underlying mechanisms for why people are reluctant to benefit from others' misfortunes. In the current studies, however, this would not explain the findings we obtained in Study 4, where participants were willing to bet on the misfortunes of others when the misfortune already occurred. Moreover, the study we 
ran on presentational concerns (Study 5) suggests that the desire to come across as moral to others does not affect people's decisions in the experiments we created. Future research could investigate in more detail how and under which circumstances moral concerns affect decision to benefit from the misfortunes of others.

Besides moral concerns, people's emotions may also affect people's decisions to benefit from others' losses. Literature on helping behavior has shown that anticipated guilt motivates people to avert threat to distant others and help those who are in need (Baumeister, Stillwell, \& Heatherton, 1994; Lindsey, 2005; Lindsey, Yun, \& Hill, 2007). In the current studies, it may very well have been the case that participants anticipated that if they would bet on the misfortunes of the other, they would feel guilty. People feel guilty when they experience emotional distress after (perceiving) having done something wrong (Baumeister et al., 1994). If participants in our studies experienced anticipated guilt, this would mean that they believed that they did something wrong, which implies that they magically believed that they could influence the outcomes of the other person. That anticipated guilt may be a potential underlying mechanism would thus support our reasoning that magical beliefs play a role in the reluctance of people to bet on the misfortunes of others. Future research could assess anticipated guilt to investigate its role in people's reluctance to benefit from the misfortunes of others.

Although participants in our five studies consistently showed a reluctance to benefit from the losses of others, this does not imply that people always refrain from betting on the misfortunes of others. Financial professionals often decide to take short positions and thereby hope to gain from others' losses (Angel \& McCabe, 2009). Also, when the chance for individual gain is large enough, people may decide to bet their 
money on the losses of others. In these situations, people might think more rationally and experience less magical beliefs. Research on magical thinking indeed shows that people experience less magical beliefs in situations where they think rationally (Risen, 2015) and feel in control (Whitson \& Galinsky, 2008). Based on the current studies, one may conclude that in these situations people may be less reluctant to benefit from others' misfortunes. Investors who are in the early stages of their careers, however, may still demonstrate magical beliefs. The current findings suggest that the experience of magical beliefs could be a reason why they operate less efficiently, or why investors in general may not always maximize their outcomes.

The current studies underscore the idea that resistance to benefit from other's chance-caused misfortune is not restricted to situations in which people benefit at the expense of others by their own doing. Even in the absence of a causal responsibility, people may choose not to benefit for the harm befalling others. By examining the role of magical beliefs, we offer new insights into the underlying mechanisms of this intriguing phenomenon, thereby extending the literature on decision-making in the moral domain. 


\section{Acknowledgments}

We thank Carey Morewedge for his insightful comments on a draft of this article. 


\section{References}

Angel, J. J., \& McCabe, D. M. (2009). The business ethics of short selling and naked short selling. Journal of Business Ethics, 85, 239-249.

Aquino, K. \& Reed, A. (2002). The self-importance of moral identity. Journal of Personality and Social Psychology, 83, 1423-1440.

Baumeister, R. F., Stillwell, A. M., \& Heatherton, T. F. (1994). Guilt: An interpersonal approach. Psychological Bulletin, 115, 243-267.

Costigan, C. (2008). Obama assassination bet in bad taste: Odds still offered. Obtained from http://www.gambling911.com/politics/obama-assassination-bet-bad-tasteodds-still-offered-110708.html.

Cushman, F. A., Young, L., \& Hauser, M. D. (2006). The role of conscious reasoning and intuition in moral judgments: Testing three principles of harm. Psychological Science, 17, 1082-1089.

Dana, J., Cain, D. M., \& Dawes, R. M. (2006). What you don't know won't hurt me: Costly (but quiet) exit in dictator games. Organizational Behavior and Human Decision Processes, 100, 193-201.

Del Marmol, T. (2011). Short selling: need or fear? Impact on financial markets and implications for regulators. Mémoire, SBS-EM, Université Libre de Bruxelles, Année académique 2010-2011.

Greene, J. D., Sommerville, R. B., Nystrom, L. E., Darley, J. M., \& Cohen, J. D. (2001). An fMRI investigation of emotional engagement in moral judgment. Science, 293, 2105-2108. 
Hauser, M. D., Cushman, F. A., Young, L., Kang-Xing Jin, R., \& Mikhail, J. (2007). A dissociation between moral judgments and justifications. Mind and Language, 22, 1-21.

Inbar, Y., Pizarro, D. A., \& Cushman, F. (2012). Benefiting from misfortune: When harmless actions are judged to be morally blameworthy. Personality and Social Psychology Bulletin, 38, 52-62.

Jordan, J., Leliveld, M. C., \& Tenbrunsel, A. E. (2015). The moral self-image scale: Measuring and understanding the malleability of the moral self. Frontiers in Psychology, 6: 1878.

Langer, E. J. (1975). The illusion of control. Journal of Personality and Social Psychology, 32, 311-328.

Lindsey, L. L. M. (2005). Anticipated guilt as behavioral motivation: An examination of appeals to help unknown others through bone marrow donation. Human Communication Research, 31, 453-481.

Lindsey, L. L. M., Yun, K. A., \& Hill, J. B. (2007). Anticipated guilt as motivation to help unknown others. Communication Research, 34, 468-480.

Mazar, N., Amir, O., \& Ariely, D. (2008). The dishonesty of honest people: A theory of self-concept maintenance. Journal of Marketing Research, 45, 633-644.

Monin, B., \& Jordan, A. H. (2009). The dynamic moral self: A social psychological perspective. Chapter 15 (pp.341-354) in D. Narvaez \& D. Lapsley (Eds), Personality, Identity, and Character: Explorations in Moral Psychology. New York: Cambridge University Press 
Morewedge, C. K., \& Buechel, E. C. (2013). Motivated underpinnings of the impact bias in affective forecasts. Emotion, 13, 1023-1029.

Morewedge, C. K., Tang, S., \& Larrick, R. P. (in press). Betting your favorite to win: Costly reluctance to hedge desired outcomes. Management Science.

Nemeroff, C., \& Rozin, P. (2000). The makings of the magical mind: The nature and function of sympathetic magical thinking. In K. S. Rosengren, C. N. Johnson, \& P. L. Harris (Eds.), Imagining the impossible: Magical, scientific, and religious thinking in children (pp. 1-34). New York: Cambridge University Press.

Post, T., Van den Assem, M. J., Baltussen, G., \& Thaler, R. H. (2008). Deal or no deal? Decision making under risk in a large-payoff game show. American Economic Review, 98, 38-71.

Preacher, K. J., \& Hayes, A. F. (2004). SPSS and SAS procedures for estimating indirect effects in simple mediation models. Behavior Research Methods, Instruments, and Computers, 36, 717-731.

Preacher, K. J., \& Hayes, A. F. (2008). Asymptotic and resampling strategies for assessing and comparing indirect effects in multiple mediator models. Behavior Research Methods, 40, 879-891.

Pronin, E., Wegner, D. M., McCarthy, K., \& Rodriguez, S. (2006). Everyday magical powers: The role of apparent mental causation in the overestimation of personal influence. Journal of Personality and Social Psychology, 91, 218-231.

Risen, J. L. (2016). Believing what we don't believe: Acquiescence to superstitious beliefs and other powerful intuitions. Psychological Review, 123, 183-207. 
Rothbart, M., \& Snyder, M. (1970). Confidence in prediction and postdiction of an uncertain outcome. Canadian Journal of Behavioural Science, 2, 38-43.

Shalvi, S., Handgraaf, M. J. J., \& De Dreu, C. K. W. (2011). People avoid situations that enable them to deceive others. Journal of Experimental Social Psychology, 47, 1096-1106.

Shaver, K. G. (1985). The attribution of blame: Causality, responsibility, and blameworthiness. New York, NY: Springer-Verlag.

Shultz, T. R., Schleifer, M., \& Altman, I. (1981). Judgments of causation, responsibility, and punishment in cases of harm-doing. Canadian Journal of Behavioral Science, $13,238-253$.

Strickland, L. H., Lewicki, R. J., \& Katz, A. M. (1966). Temporal orientation and perceived control as determinants of risk-taking. Journal of Experimental Social Psychology, 2, 143-151.

Tang, S., Morewedge, C. M., Larrick, R. P, \& Klein, J. G. (2017). Disloyalty aversion: Greater reluctance to bet against close others than the self. Organizational Behavior and Human Decision Processes, 140, 1-13.

Thompson, S. C., Armstrong, W., \& Thomas, C. (1998). Illusions of control, underestimations, and accuracy: A control heuristic explanation. Psychological Bulletin, 123, 143-161.

Weiner, B. (1995). Judgments of responsibility: A foundation for a theory of social conduct. New York, NY: Guilford.

Whitson, J. A., \& Galinsky, A. D. (2008). Lacking control increases illusory pattern perception. Science, 322, 115-117. 
Wortman, C. B., Costanzo, P. R., \& Witt, T. R. (1973). Effects of anticipated performance on the attributions of causality to self and others. Journal of Personality and Social Psychology, 27, 372-381. 


\section{Authors' biographies}

Gert-Jan Lelieveld is assistant professor at Leiden University. His research concentrates on social decision-making, social exclusion, and the function of emotions in settings of interdependence.

Yoel Inbar is assistant professor at the University of Toronto. His research concentrates on how intuitions and emotions affect our social, political, and moral beliefs.

Eric van Dijk is professor at Leiden University. His research concentrates on the understanding of economic and social decision-making. 


\section{Table 1}

Participant betting choices by condition.

\begin{tabular}{cccc}
\hline & \multicolumn{3}{c}{ Participants' bets } \\
\cline { 2 - 4 } Condition & With the odds & Abstain & Against the odds \\
\hline $\begin{array}{c}\text { "Win" bet has } \\
\text { better odds }\end{array}$ & $79.2 \%(42 / 53)$ & $1.9 \%(1 / 53)$ & $18.9 \%(10 / 53)$ \\
$\begin{array}{c}\text { "Lose" bet has } \\
\text { better odds }\end{array}$ & $31.4 \%(16 / 51)$ & $11.8 \%(6 / 51)$ & $56.9 \%(29 / 51)$ \\
\hline
\end{tabular}




\begin{tabular}{|c|c|c|}
\hline \multicolumn{3}{|c|}{$€ 13,000$} \\
\hline$€ 0.01$ & \multirow{13}{*}{$\begin{array}{l}\text { close-up of the } \\
\text { contestant is } \\
\text { shown here }\end{array}$} & $€ 7,500$ \\
\hline$€ 0.20$ & & $€ 10,000$ \\
\hline$€ 0.50$ & & $€ 25,000$ \\
\hline$€ 1$ & & $€ 50,000$ \\
\hline$€ 5$ & & $€ 75,000$ \\
\hline$€ 10$ & & $€ 100,000$ \\
\hline$€ 20$ & & $€ 200,000$ \\
\hline$€ 50$ & & $€ 300,000$ \\
\hline$€ 100$ & & $€ 400,000$ \\
\hline$€ 500$ & & $€ 500,000$ \\
\hline$€ 1,000$ & & $€ 1,000,000$ \\
\hline$€ 2,500$ & & $€ 2,500,000$ \\
\hline$€ 5,000$ & & $€ 5,000,000$ \\
\hline
\end{tabular}

Figure 1

“Miljoenenjacht” game board. Numbers in columns are prize values. Available prizes have white backgrounds, unavailable (i.e., eliminated) prizes have gray backgrounds. The large number at the top is the bank's current offer. Figure reproduced with permission from Post, Van den Assem, Baltussen, and Thaler (2008). 